\title{
Solvatochromic fluorescent probes in bicontinuous microemulsions
}

\author{
M.E.C.D.R. Oliveira ${ }^{a}{ }^{*}$, G. Hungerford ${ }^{a}$, M. da G. Miguel $^{\text {b }}$, H.D. Burrows ${ }^{\text {b }}$ \\ ${ }^{\mathrm{a}}$ Departamento de Física, Universidade do Minho, 4700-320 Braga, Portugal \\ ${ }^{\mathrm{b}}$ Departamento de Química, Universidade de Coimbra, 3004-535 Coimbra, Portugal
}

Received 31 August 2000; revised 24 October 2000; accepted 24 October 2000

\begin{abstract}
The fluorescence probes nile red and prodan have been used to study the structure of the bicontinuous phase of $\mathrm{C}_{12} \mathrm{E}_{5} / \mathrm{alkane} /$ water microemulsions. For nile red the steady state fluorescence spectrum show contributions from probe located in alkane and surfactant rich regions, together with indications of surfactant hydration. Fluorescence lifetime measurements show multiexponential decay kinetics consistent with this idea. The steady state fluorescence spectrum of prodan in the bicontinuous region also suggests different environments for the probe. Fluorescence anisotropy measurements using rhodamine 6G show that this bicontinuous phase is more ordered than either oil in water or water in oil microemulsions. The fluorescence technique provides a valuable tool with which to elucidate the structure of these complex systems. () 2001 Elsevier Science B.V. All rights reserved.
\end{abstract}

Keywords: Bicontinuous microemulsions; $\mathrm{C}_{12} \mathrm{E}_{5}$; Prodan; Nile red; Fluorescence spectroscopy

\section{Introduction}

Aggregation of amphiphilic molecules in solution can produce a variety of structures, including micelles, microemulsions and liquid crystals. Elucidating the microstructure of these domains is vital for a detailed understanding of their macroscopic properties. We have been particularly interested in the phase behaviour of the non-ionic surfactant $\mathrm{C}_{12} \mathrm{E}_{5}$ $\left(\mathrm{C}_{12} \mathrm{H}_{25}\left(\mathrm{OCH}_{2} \mathrm{CH}_{2}\right)_{5} \mathrm{OH}\right)$ in the presence of water and an alkane. Mixtures of $\mathrm{C}_{12} \mathrm{E}_{5}$ and water can exhibit micellar, lamellar, hexagonal and cubic phases [1]. In the presence of oil, the three component system of $\mathrm{C}_{12} \mathrm{E}_{5} /$ alkane/water shows a variety of single-phase and two-phase regions [2]. Of particular interest are

\footnotetext{
* Corresponding author. Tel.: +351-53-60-4325; fax: +351-5367-8981.

E-mail address: beta@fisica.uminho.pt (M.E.C.D.R. Oliveira).
}

the microemulsion phases, which are water continuous at low oil content and oil continuous at high oil content, but can display bicontinuous phases, depending on composition and temperature $[3,4]$. We have shown that pyrene fluorescence provides an excellent probe for monitoring the transitions between these microemulsion phases and elucidating their dynamics [5].

In this communication, we have employed three fluorescent probes, prodan, nile red and 4-di-1-asp (pyridinium, 4-(2-(dimethylamino)phenyl)-1-methyl iodide) to study the bicontinuous phase. These have different affinities, nile red is strongly hydrophobic [6], 4-di-1-asp is hydrophilic [7], whilst prodan is able to partition between all domains, and shows strongly solvatochromic fluorescence and absorption spectra [8]. Additional information on structural ordering in the bicontinuous phase has been obtained using rhodamine $6 \mathrm{G}$ fluorescence anisotropy. 
Table 1

Rotational correlation times $\left(T_{\mathrm{r}}\right)$ for rhodamine $6 \mathrm{G}$ and the derived viscosity for the system $\mathrm{C}_{12} \mathrm{E}_{5} /$ water/tetradecane at an oil fraction of 0.45 , where $r_{0}$ is the initial anisotropy, $r_{\infty}$ is the limiting anisotropy and the goodness of fit is given by the $\chi^{2}$ value

\begin{tabular}{llllll}
\hline Temperature $\left({ }^{\circ} \mathrm{C}\right)$ & $T_{\mathrm{r}}(\mathrm{ns})$ & $r_{0}$ & $r_{\infty}$ & $\chi^{2}$ & Viscosity $\left(\times 10^{-3}\right) / \mathrm{Nm}^{-2} \mathrm{~s}$ \\
\hline 34 & $0.64 \pm 0.52$ & 0.079 & 0.01 & 1.09 & 3.7 \\
45 & $1.35 \pm 0.12$ & 0.271 & 0.02 & 1.04 & 8.1 \\
57 & $0.97 \pm 0.15$ & 0.216 & 0.01 & 1.07 & 6.0 \\
\hline
\end{tabular}

\section{Experimental}

The ternary system containing polyoxyethylene 5 lauryl ether $\left(\mathrm{C}_{12} \mathrm{E}_{5}\right)$, tetradecane (both Sigma) and water was prepared by combining solutions of $16.6 \% \mathrm{C}_{12} \mathrm{E}_{5}$ in water with $16.6 \% \mathrm{C}_{12} \mathrm{E}_{5}$ in tetradecane $\left(\mathrm{C}_{14} \mathrm{H}_{30}\right)$ to provide a weight fraction of 0.45 of tetradecane. This was then added to a cuvette, in which the selected amount of probe had been deposited by evaporation from a stock solution in ethanol. The samples were then placed in an ultrasonic bath for mixing and then left for some time to stabilise. The steady state fluorescence and absorption measurements were performed using Spex Fluorolog and Shimadzu UV-3101PC spectrometers, respectively. The time-resolved fluorescence measurements were performed using a single-photon counting spectrometer equipped with a nanosecond pulsed excitation source. In the case of rhodamine $6 \mathrm{G}$ this was a coaxial flashlamp filled with hydrogen gas. Otherwise a $490 \mathrm{~nm}$ LED excitation head (NanoLED, IBH Ltd) was used, with the equipment running in reverse mode because of the high repetition rate $(800 \mathrm{kHz})$. The detection of the fluorescence, monitored at a right angle to the excitation, was made using a Philips XP2020 photomultiplier for the rhodamine 6G samples and a Hamamatsu R2949 for nile red. The fluorescence decays were measured to 10,000 counts in the peak and the instrumental response functions were recorded subsequently using a scattering solution. The decays were analysed as a sum of exponentials, using a non-linear least squares reconvolution analysis (IBH Consultants Ltd), of the form,

$I(t)=\sum_{i=1}^{n} \alpha_{i} \exp \left(-t / \tau_{i}\right)$

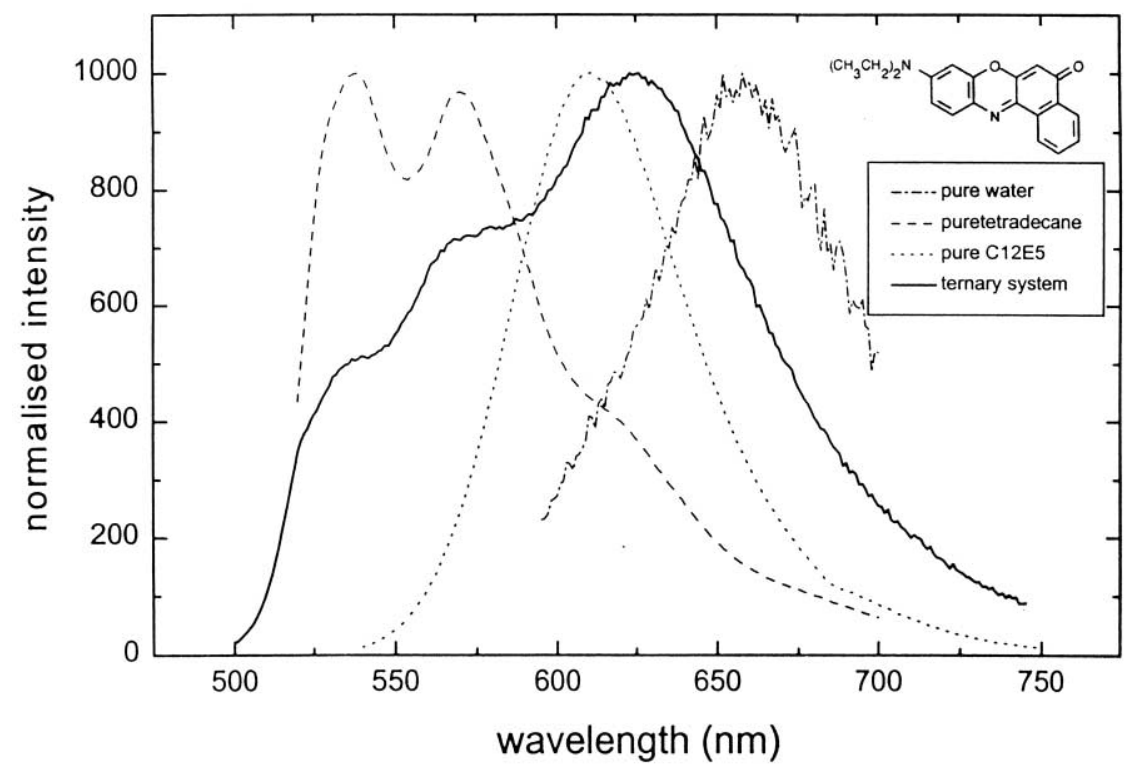

Fig. 1. Fluorescence spectra for nile red in the ternary system $\mathrm{C}_{12} \mathrm{E}_{5} /$ alkane/water and the component pure solvents. 
Table 2

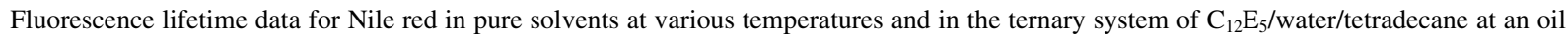
fraction of 0.45 for different emission wavelengths (lifetime in water reported as $0.65 \mathrm{~ns}$ in Ref. [10])

\begin{tabular}{|c|c|c|c|c|c|c|c|c|c|}
\hline System & Temperature $\left({ }^{\circ} \mathrm{C}\right)$ & $\lambda_{\mathrm{exc}}, \lambda_{\mathrm{em}}(\mathrm{nm})$ & $\tau_{1}(\mathrm{~ns})$ & $\alpha_{1}$ & $\tau_{2}(\mathrm{~ns})$ & $\alpha_{2}$ & $\tau_{3}(\mathrm{~ns})$ & $\alpha_{3}$ & $\chi^{2}$ \\
\hline \multirow[t]{3}{*}{ Pure tetra-decane } & 34 & 500,550 & $2.76 \pm 0.02$ & & & & & & 1.10 \\
\hline & 45 & 500,550 & $2.44 \pm 0.02$ & & & & & & 1.20 \\
\hline & 57 & 500,550 & $2.09 \pm 0.01$ & & & & & & 1.14 \\
\hline \multirow[t]{3}{*}{ Pure $\mathrm{C}_{12} \mathrm{E}_{5}$} & 34 & 490,600 & $0.39 \pm 0.18$ & 0.30 & $2.44 \pm 0.45$ & 0.27 & $4.27 \pm 0.08$ & 0.43 & 1.08 \\
\hline & 45 & 490,600 & $0.43 \pm 0.15$ & 0.33 & $2.44 \pm 0.45$ & 0.27 & $4.30 \pm 0.09$ & 0.40 & 1.07 \\
\hline & 57 & 490,600 & $0.46 \pm 0.21$ & 0.30 & $1.97 \pm 0.30$ & 0.33 & $4.19 \pm 0.07$ & 0.37 & 1.09 \\
\hline \multirow[t]{4}{*}{$\mathrm{C}_{12} \mathrm{E}_{5} /$ tetra-decane/water } & 45 & 490,550 & $0.10 \pm 0.10$ & 0.68 & $1.28 \pm 0.12$ & 0.17 & $3.20 \pm 0.35$ & 0.15 & 1.11 \\
\hline & 45 & 490,600 & $1.19 \pm 0.15$ & 0.35 & $3.16 \pm 0.03$ & 0.65 & & & 1.08 \\
\hline & 45 & 490,650 & $0.55 \pm 0.07$ & -0.36 & $2.94 \pm 0.03$ & 0.64 & & & 1.26 \\
\hline & 45 & 490,700 & $0.54 \pm 0.06$ & -0.38 & $2.95 \pm 0.03$ & 0.62 & & & 1.20 \\
\hline
\end{tabular}

The pre-exponential factors $\left(\alpha_{i}\right)$ are shown normalised to 1 and the errors in the decay times $\left(\tau_{i}\right)$ are given as 3 standard deviations. The goodness of fit was judged both in terms of a chi-squared $\left(\chi^{2}\right)$ value, usually taken as below 1.2 for an acceptable fit, and weighted residuals.

\section{Results and discussion}

Fluorescence anisotropy measurements using rhodamine $6 \mathrm{G}$ provide information on changes in fluidity on going from either the water continuous or oil continuous microemulsions to the bicontinuous system (Table 1). The higher viscosity observed in the bicontinuous region, which occurs at $45^{\circ} \mathrm{C}$ [2], clearly indicates a more ordered structure in which the dye rotation is more restricted.

Comparison of the fluorescence spectra of nile red in the bicontinuous phase of the ternary system with those of the component pure compounds (Fig. 1) shows major contributions from probe localised in both pure oil and surfactant rich zones. However, the long wavelength maximum is red shifted relative

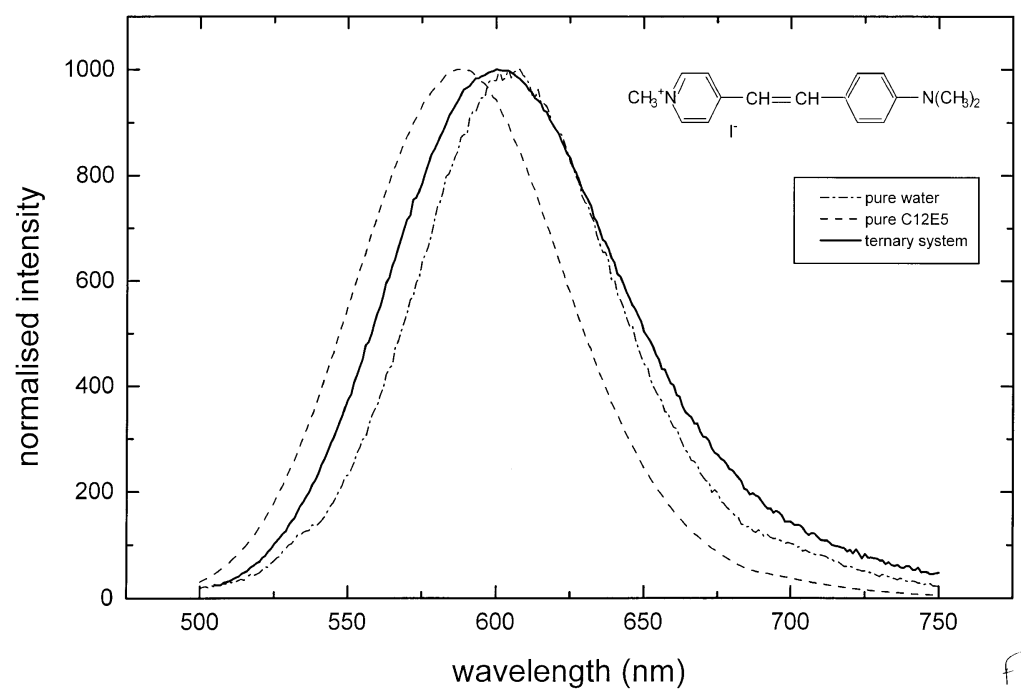

Fig. 2. Fluorescence spectra for 4-di-1-asp in the ternary system $\mathrm{C}_{12} \mathrm{E}_{5} /$ alkane/water and the component pure solvents. 


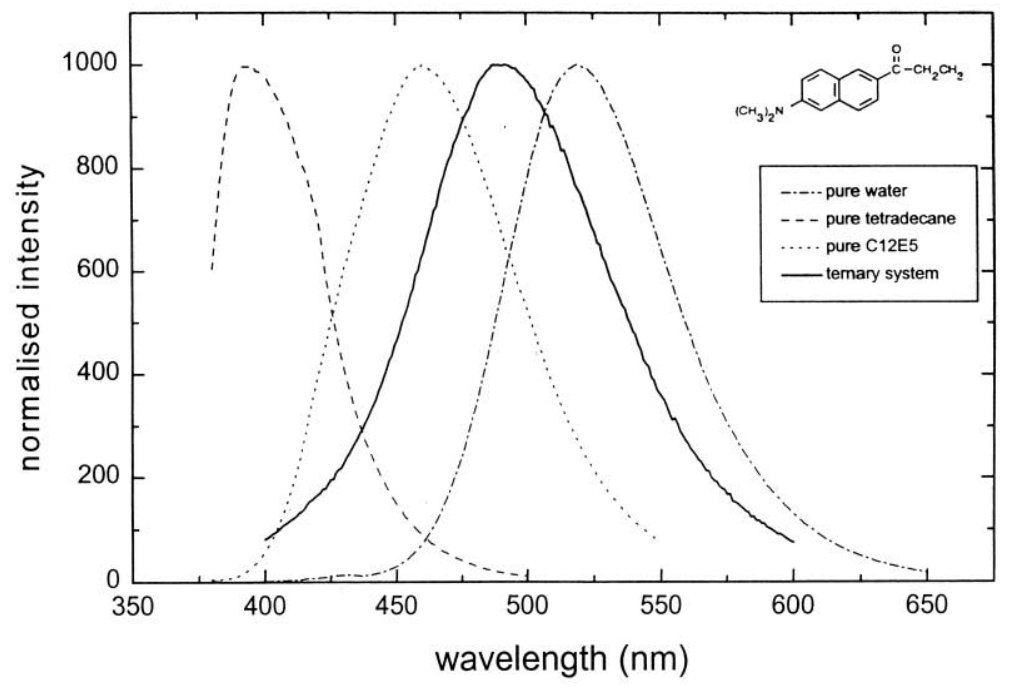

Fig. 3. Fluorescence spectra for prodan in the ternary system $\mathrm{C}_{12} \mathrm{E}_{5} / \mathrm{alkane} /$ water and the component pure solvents.

to pure $\mathrm{C}_{12} \mathrm{E}_{5}$, indicating increased polarity, which may be associated with hydration of the poly(ethylene oxide) chains. Further confirmation for these locations comes from the fluorescence lifetime data (Table 2), which were single exponential in pure alkane, but which required multiexponential fits for both pure surfactant and the bicontinuous phase. The latter showed a pronounced wavelength dependence, similar to what has been reported for this probe in viscous solutions and micelles [9]. Whilst detailed analysis of this behaviour is beyond the scope of this work, the results lend support to different sites for the probe.

The fluorescence spectrum (Fig. 2) was also measured for the hydrophilic probe 4-di-1-asp in the bicontinuous phase. The photophysical properties of this probe have been previously reported [7], and found to depend on temperature and viscosity. In the system we have studied it appears to be localised near the head region of the $\mathrm{C}_{12} \mathrm{E}_{5}$, close to the aqueous domain. This is in agreement with the low solubility of the probe in alkanes.

Fluorescence studies of prodan in the bicontinuous phase of the ternary system and in the pure components (Fig. 3) suggest that it is predominantly located at the $\mathrm{C}_{12} \mathrm{E}_{5}$ /water boundary, but also shows (see short wavelength shoulder) some tendency to sit in a hydrocarbon rich region. Studies in reverse micelles using this probe also point to multiple partitioning sites $[11,12]$.

These results clearly show the value of these solvatochromic fluorescence probes in determining the polarity and solute distribution in bicontinuous $\mathrm{C}_{12} \mathrm{E}_{5}$ /alkane/water microemulsions.

\section{Acknowledgements}

We are grateful to Dr E.M.S. Castanheira for her invaluable assistance with some of the experiments. Financial support is acknowledged from the Fundação para a Ciência e a Tecnologia (PRAXIS XXI).

\section{References}

[1] D.J. Mitchell, G.J.T. Tiddy, L. Waring, T. Bostock, M.P. McDonald, J. Chem. Soc. Faraday Trans. 179 (1983) 975.

[2] U. Olsson, K. Shinoda, B. Lindman, J. Phys. Chem. 90 (1986) 4083.

[3] U. Olsson, H. Wennerstrom, Adv. Colloid Interface Sci. 49 (1994) 113.

[4] B. Lindman, U. Olsson, O. Soderman, in: P. Kumar, K.L. Mittal (Eds.), Handbook of Microemulsion Science and Technology, Marcel Dekker, New York, 1999 (Chap. 10).

[5] M.E.C.D.R. Oliveira, G. Hungerford, E.M.S. Castanheira, M. da G. Miguel, H.D. Burrows, J. Fluoresc. 10 (4) (2000) 347353 (in press).

[6] P. Greenspan, S.D. Fowler, J. Lipid Res. 26 (1985) 781. 
[7] B. Strehmel, W. Rettig, J. Biomed. Opt. 1 (1996) 98.

[8] J. Slavik, J. Fluoresc. 7 (1997) 49S.

[9] M.M.G. Krishna, J. Phys. Chem. A 103 (1999) 3589.

[10] A. Datta, D. Mandal, S.K. Pal, K. Bhattacharyya, J. Phys. Chem. B 101 (1997) 10221.
[11] K.K. Karuktis, A.A. Frazier, C.T. Loftus, A.S. Tuan, J. Phys. Chem. B 102 (1998) 8163.

[12] B. Sengupta, J. Guharay, P.K. Sengupta, Spectrochim. Acta Part A 56 (2000) 1433. 